\title{
A HISTORICIDADE DAS TEORIAS INTERPRETATIVAS DO PROCESSO SAÚDE-DOENÇA*
}

\section{THE HISTORICITY OF THE HEALTH-ILLNESS PROCESS INTERPRETATIVE THEORIES}

Maria Amélia de Campos Oliveira** Emiko Yoshikawa Egry***

OLIVEIRA, M.A.C.; EGRY, E.Y. A historicidade das teorias interpretativas do processo saúde-doença. Rev.Esc.Enf.USP, v. 34, n. 1, p. 9-15, mar. 2000.

\section{RESUMO}

As diferentes teorias interpretativas do processo saúde-doença identificáveis ao longo da história têm como decorrência distintos projetos de intervenção sobre a realidade, em resposta a necessidades sociais. Até o século XIX, tais teorias podem ser sintetizadas nas vertentes ontológica e dinâmica. Na concepção ontológica, a doença assume o caráter de uma entidade natural ou sobrenatural, externa ao corpo humano, que se manifesta ao invadi-lo. A concepção dinâmica vê a doença como produto da desarmonia entre forças vitais, sendo que o restabelecimento da saúde advém da restauração do equilíbrio Ao final do século XVIII, predominavam na Europa como forma de explicação para o adoecimento humano os paradigmas sócioambientais, vinculados à concepção dinâmica, tendo se esboçado as primeiras evidências da determinação social do processo saúde-doença. Com o advento da Bacteriologia, a concepção ontológica firmou-se vitoriosa e suas conquistas levaram ao abandono dos critérios sociais na formulação e no enfrentamento dos problemas de saúde das populações. Na atualidade, identifica-se o predominio da multicausalidade, com ênfase nos condicionantes individuais. Como alternativa para a sua superação, propõe-se a articulação das dimensões individual e coletiva do processo saúde-doença, em consonância com a Teoria da Intervenção Práxica de Enfermagem em Saúde Coletiva.

PALAVRAS-CHAVE: Processo saúde-doença. Enfermagem em Saúde Comunitária.

\begin{abstract}
The interpretative theories of the health-illness process that can be identified through History have as consequence intervention projects upon the reality, in response to social needs. Until the 19 century, they could be synthesized in two main streams: ontologic and dynamic. In the ontologic conception, illness assumes the character of a natural or supernatural entity, external to the human body, that shows itself when invading it. The dynamic conception sees illness as a product of the disharmony among vital forces, and the re-establishment of the health comes of the restoration of this balance. At the end of the 18 century, the social-environmental paradigms prevailed in Europe as forms of explanation for human illness, linked to the dynamic conception, and the first evidences of the social determination of the health-illness process were formulated. The onset of the Bacteriologic Era made the ontologic conception victorious and its conquests led to the abandon of the social approaches to face the populations health problems. At the present time, one can identify the prevalence of the multicausal theory, with emphasis in the individual conditionings. This paper proposes the articulation of the individual and collective dimensions of the health-illness process, in consonance with the Theory of Nursing Praxical Intervention in Collective Health.
\end{abstract}

KEYWORDS: Health disease process. Public health nursing.

* Originalmente parte da tese OLIVEIRA, M. A de C. A adolescência, o adolescer e o adolescente: re-significação a partir da determinação social do processo saúde-doença. São Paulo, 1997.142p. Tese (Doutorado) - Escola de Enfermagem,

Universidade de São Paulo.

** Professora Doutora do Departamento de Enfermagem em Saúde Coletiva da Escola de Enfermagem da Universidade de São Paulo

*** Professora Titular do Departamento de Enfermagem em Saúde Coletiva da Escola de Enfermagem da Universidade de São Paulo. 


\section{INTRODUÇÃO}

Ao longo da história, foram sendo forjadas diferentes teorias interpretativas sobre o processo saúde-doença, como conseqüência da atividade racional humana na busca de inferências causais para a doença. Essas teorias são, em última instância, expressões de determinadas maneiras de pensar o mundo e traduzem projetos filosóficos diversos, quando não antagônicos.

A busca da causalidade, é preciso destacar, tem um caráter instrumental, na medida em que as categorias interpretativas que dela resultam dão suporte a projetos de intervenção sobre a realidade. As concepções a respeito do objeto de atuação são elaborações intelectuais prévias ao projeto concreto de intervenção que, por sua vez, responde a necessidades sociais. Assim, a concepção de 'doença' existente em uma determinada época é um instrumento de trabalho historicamente apropriado para a reprodução daquela articulação na estrutura social particular analisada". (CASTELLANOS; BERTOLOZZI, 1991 :9)

\section{A CONSTITUIÇÃO HISTÓRICA DAS CONCEPÇÕES SOBRE A SAÚDE E A DOENÇA}

Segundo CANGUILHEM (1978:19-23), até o século $\mathrm{XIX}$, as formas de representação da doença podiam ser sintetizadas em duas vertentes fundadas na unicausalidade: a ontológica e a dinâmica. Predominava na Antigüidade, especialmente entre os assírios, egipcios, caldeus e hebreus, a concepção ontológica que "... atribuía à enfermidade um estatuto de causa única e de entidade, sempre externa ao ser humano e com existência própria - um mal, sendo o doente, o ser humano ao qual essa entidade-maleficio se agregou: o corpo humano é tomado com receptáculo de um elemento natural ou espirito sobrenatural que, invadindo-o, produz a 'doença'; sem haver qualquer participação ou controle desse organismo no processo de causação".

Essa concepção, que LUZ (1979:96) define como "organicista, localizante e mecanicista em termos de causalidade", ainda subsiste no pensamento contemporâneo, apesar das transformações históricas de que foi alvo. Para CANGUILHEM (1978), ela se faz presente nas interpretações da doenças carenciais, infecciosas e parasitárias.

A hegemonia da interpretação mágico-religiosa não impediu o desenvolvimento da observação e da prática empírica, cuja acumulação resultou em sistemas teóricos empiricistas vinculados a uma concepção dinâmica da causalidade, identificável nas antigas medicinas hindu e chinesa (FACCHINI, 1994). Nelas a doença era vista como o produto do desequilíbrio ou desarmonia entre os princípios ou forças básicas da vida, mas compreendia também a busca do reequilíbrio. Ou, nas palavras de CANGUILHEM (1978:20-1), "a doença é uma reação generalizada com intenção de cura". Há, por assim dizer, uma naturalização da doença em que o ser humano deixa de ter papel passivo, podendo ativamente buscar diferentes procedimentos terapêuticos para a restauração de suas forças vitais.

Hipócrates, considerado o pai da medicina moderna, reconhecia a doença como parte da natureza, dando prosseguimento à vertente dinâmica, no processo gradual de transição da consciência mítica ao pensamento racional, a que se fez referência e no qual a filosofia grega teve papel fundamental. Para esse médico grego, a saúde era a expressão de uma condição de equilíbrio do corpo humano, obtida através de um modo de vida ideal, que incluía nutrição, excreção, exercício e repouso adequados (ROSEN, 1994). A medicina hipocrática dos séculos V e IV a.C. valorizava a prática clínica e a observação da natureza, à qual atribuía grande importância na causação das doenças, nela podendo ser encontradas as origens da corrente ecológica moderna (BARATA,1990). Progressivamente, a noção de causalidade foi se tornando mais complexa e esboçaram-se então as primeiras hipóteses sobre o contágio.

Durante a Idade Média, a medicina ocidental experimentou um relativo retrocesso pois, ainda que mantidos os princípios hipocráticos, o Cristinianismo levou ao progressivo abandono da prática clínica em favor de uma maior preocupação com a salvação do espírito. Mas já ao final do Medievo, as freqüentes guerras e o aumento das epidemias na Europa trouxeram de volta a preocupação com as formas de transmissão das doenças, então atribuídas a influências cósmicas, à bruxaria ou ao envenenamento da água e do ar por grupos estigmatizados, como judeus e leprosos. (ANDERY et al., 1988)

Sob a poderosa influência do paradigma cartesiano, a ciência médica desenvolveu-se rapidamente durante os séculos XVII e XIX. Experimentou considerável progresso com o desenvolvimento da Anatomia Humana, a partir das cuidadosas observações de Vesalius na dissecação de cadáveres. Seu estudo possibilitou o surgimento de uma nova disciplina, a Fisiologia, que buscava explicar o funcionamento normal do corpo humano. Um sistema classificatório para as doenças foi uma das maiores contribuições dos primeiros estágios da medicina científica, originário de uma outra disciplina científica, a Patologia. Os projetos terapêuticos de então eram ainda bastante limitados e, ainda que fizessem uso de drogas, antes de 1700 não eram conhecidas mais que duas dúzias de substâncias eficazes (BANTA; DAHUCE, 1993). Juntas, a Anatomia, a Fisiologia e a Patologia, esta com o seu sistema classificatório das doenças, permitiram que se realizasse "o deslocamento epistemológico - e clínico - da medicina moderna, de uma arte de curar individuos doentes para uma disciplina das doenças". (LUZ, 1979:83) 
Já a revolução sanitária do século XIX pode ser visualizada como um conjunto de intervenções sistemáticas sobre o ambiente físico para torná-lo mais seguro, apoiando-se em abordagens tecnológicas que remontam à Antigüidade clássica. Já haviam sido lançadas as bases da Epidemiologia, voltada para a observação e o registro da ocorrência das doenças nas populações quando a teoria contagionista superou a atmosférico-miasmatica, após um embate que perdurou do século XVI ao XIX. (ROSEN,1994; CZERESNIA, 1997)

Quando as tentativas de explicar o contágio resultaram na compreensão de que pequenas partículas invisiveis seriam as causadoras da doença, foi retomada a vertente ontológica da causalidade, em detrimento da concepção mais totalizadora representada pela medicina hipocrática. Iniciava-se assim a era bacteriológica, com as descobertas de Pasteur, Koch e outros para a cura das doenças infecciosas. O desenvolvimento das vacinas para a prevenção das doenças representou outro grande avanço. Coube a Jenner o crédito pelo primeiro uso médico da cowpox em 1796. No final de 1800, Pasteur atenuou microorganismos para produzir vacinas, inclusive contra a raiva. O isolamento dos virus em 1935 e seu subseqüente crescimento em culturas de células tornou possivel o desenvolvimento das vacinas contra a poliomielite, o sarampo e a rubéola. (BANTA; DAHUCE, 1993)

Será preciso, contudo, examinar mais detidamente o momento histórico à época da constituição da Epidemiologia, um conjunto de saberes e práticas voltado para a dimensão coletiva do fenômeno saúde-doença, como resultado do agravamento das condições de vida das populações dos conglomerados urbanos na fase inicial da industrialização. (SILVA, 1979)

Os paradigmas sócio-ambientais predominavam como forma de explicação para a origem das doenças. Miséria e miasmas eram invocados para explicar a disseminação das enfermidades. Os estudos de Chadwick sobre as causas sociais da diminuição absoluta da população inglesa e de John Snow sobre o caráter transmissivel da cólera instituíram as bases metodológicas da Epidemiologia (FACCHINI,1994; SILVA,1990). Esboçavam-se as primeiras evidências da determinação social do processo saúde-doença e os primeiros modelos estatais de interferência na saúde das coletividades, a saúde pública inglesa e a medicina social francesa. Tais modelos articulavam-se aos movimentos ideológicos do sanitarismo e da medicina social, estes congruentes às correntes de pensamento vigentes na época e em seus locais de origem, Inglaterra e Europa Ocidental, respectivamente. (SILVA, 1979)

A reforma sanitária, como movimento político, assim como a saúde pública, seu projeto técnico de ação, no início pouco contaram com a adesão dos médicos, de modo que as medidas de saneamento do meio foram implementadas por engenheiros e administradores públicos. Só gradativamente a medicina abraçou a causa da saúde pública, pondo a seu serviço um instrumental técnico em contínua expansão, especialmente após a Era Bacteriológica. (SILVA,1979; SALUM, BERTOLOZZI, OLIVEIRA, 1998)

No projeto da saúde pública de então evidenciavase, tal como ainda ocorre, a ação supletiva do Estado, de forma sempre limitada e complementar à iniciativa privada, para a solução dos problemas cuja magnitude excedesse as possibilidades da intervenção individual. Contemporânea do movimento sanitário inglês, a medicina social, por sua vez, originou-se na França, disseminando-se posteriormente para a Alemanha. Fundada no reconhecimento empírico das relações entre a doença e as condições sociais, desenvolveuse mais lentamente que a saúde pública, vindo a institucionalizar-se tardiamente nos "Estados de bem-estar social" da atualidade (SILVA,1979). "A característica mais geral desta transformação é o fato de a medicina se tornar social.(...) O objeto da medicina começa a se deslocar, portanto, da doença para a saúde". (MACHADO et al., 1978:248)

$\mathrm{O}$ movimento higienista possibilitou à medicina substituir com seus preceitos para uma vida sadia a ordem moral religiosa numa sociedade progressivamente mais laica. Entretanto, a bacteriologia firmou-se como a concepção vitoriosa e as suas conquistas acabaram por levar ao abandono dos critérios sociais na formulação e solução dos problemas de saúde das populações que vinham sendo sistematicamente aplicados pela "polícia médica" alemã, pela "medicina urbana" francesa e pelo "sanitarismo" inglês. (NUNES, 1986)

$\mathrm{Na}$ esteira da "revolução científica" desencadeada pela Bacteriologia, e na crença da sua eficácia, a medicina julgou-se capaz de prosseguir em rumo fixo no estudo das doenças infeciosas, prescindindo de quaisquer considerações sociais. Os descobrimentos do final do século passado e do alvorecer deste lançaram as bases dos futuros marcos de referência da medicina moderna: o combate das enfermidades agudas através da imunização e do tratamento; a ênfase na definição biológica das doenças; a crença na possibilidade de sua erradicação e a reorganização do ensino médico, com a institucionalização do movimento científico. Estas duas últimas tarefas foram levadas a cabo inicialmente nos Estados Unidos, com o Informe Flexner, repercutindo daí para outros países, especialmente os da América Latina. (SALUM; BERTOLOZZI; OLIVEIRA, 1998)

GARCIA (1995:71), comentando sobre a relação de reciprocidade entre a investigação em saúde e a estrutura social, afirma que na prática médica [e, por extensão, nas práticas de saúde] a concepção e a proposição de ações são originárias das relações que os indivíduos estabelecem com o mundo objetivo, 
"en las relaciones prácticas del hombre con las cosas y en las relaciones dos hombres entre si". Daí que a investigação bacteriológica e parasitológica que se desenvolveu nas Américas de 1880 a 1930 estivesse ligada aos problemas da produção agroexportadora, sendo sucedida no decênio de 1930 a 1950 pela investigação básica e clínica, impulsionada pelo crescimento hospitalar ocasionado pela industrialização e, a partir dos anos 70 , pelos estudos voltados à racionalização dos serviços de saúde, face à diminuição dos gastos estatais destinados ao setor. (GARCIA,1995)

Foi somente após a II Guerra Mundial, quando já se havia conseguido um controle relativo das principais doenças transmissiveis, que a abordagem social dos fenômenos de saúde-doença foi reincorporada, frente à constatação de que um contingente expressivo de individuos de grupos sociais desfavorecidos permanecia à margem desses avanços, em precárias condições de existência e, por conseguinte, de saúde. Os interesses voltaramse gradativamente para as enfermidades crônicas e para as não-infecciosas, frente às mudanças demográficas e ao envelhecimento da população dos países desenvolvidos. A prática médica havia se deslocado quase que exclusivamente para o hospital, daí a necessidade de melhor conhecê-lo, o que se materializou em inúmeros estudos sobre as organizações oficiais, as profissões, as atitudes e os padrões culturais. (NUNES, 1986)

Vê-se, portanto, que as concepções sobre a saúde e a doença são limitadas pelo desenvolvimento teóricoconceitual da ciência e, sobretudo, por condicionantes ideológicos que tornam determinadas opções conceituais mais legitimas e mais potentes que outras. Ancoram-se em marcos teóricos e filosóficos distintos e expressamse modelos de causalidade que, por sua vez, desdobramse em formas de registro, mensuração, análise, interpretação e intervenção correspondentes. Retratam a diversidade conceitual e metodológica resultante das transformações dos marcos de inferência causal ao longo da história da constituição desses saberes - das crenças mágico-religiosas, passando pelo empirismo racional, até à ciência moderna.

\section{AS CONCEPÇÕES SOBRE A SAÚdE E A DOENÇA NA ÁTUALIDADE}

$\mathrm{Na}$ atualidade, a saúde é freqüentemente pensada em termos negativos, como a ausência de doença. A Organização Mundial da Saúde, ao definir a saúde como "o completo bem-estar fisico, mental e não apenas a ausência de doença", propôs-se justamente a superar essa negatividade através de um conceito integrador que, mais que um conjunto de negativas, pretende designar a inexistência de qualquer condição indesejável. De acordo com ABED (1993), as muitas críticas feitas a essa definição referem-se ao fato de que nela a saúde aparece como algo absoluto e indivisível, como um valor demasiadamente genérico, que faz uso de um termo estático como "estado" para designar algo que é essencialmente mutável e de outro pouco preciso como "bem-estar".

Os possiveis ganhos em abrangência dessa definição trazem consigo o risco de que o conceito torne-se assim finalidade de toda atividade humana e não de uma atividade orientada para a saúde. Além disso, trata-se de uma concepção polar, na medida em um dos pólos está o bem-estar no seu sentido mais amplo, em certa medida equivalente ao ideal platônico do BEM, e no outro a ausência pura e simples de circunstâncias biológicas negativas, tais como a doença, a incapacidade ou a morte. Entretanto, mesmo o senso comum sugere um contínuo de significados entre saúde e doença, cujas fronteiras pouco nítidas não impedem que se reconheçam as suas diferenças. (EVANS; STODDART, 1990)

Para BARRETO;CARMO (1994), na análise contemporânea da causalidade, a ênfase tem recaído sobre seus condicionantes micro-epidemiológicos ou individuais, pouco sendo dito sobre aqueles a que denominam macro-epidemiológicos ou coletivos. $\mathrm{Na}$ tentativa de tipificar alternativas entre esses dois pólos de causalidade, o individual e o coletivo, Rose apud BARRETO; CARMO,1995 identifica uma estratégia de intervenção de base individual que busca a caracterização de "grupos de risco" em contraposição a outra de base coletiva a que designa "estratégia populacional". Segundo ele, a desvantagem em relação à adoção da estratégia populacional reside na dificuldade de sua implementação, por deslocar a questão da saúde para fora da organização do cuidado médico ou, dito de outra forma, para fora do âmbito das políticas de assistência à saúde.

BARRETO;CARMO (1994) identificam na atualidade o predomínio do modelo da determinação multicausal, que atribui a gênese da doença a múltiplos fatores interrelacionados em redes de causalidade. A despeito da sua positividade, que lhe vem permitindo manter-se como hegemônico, as insuficiências do modelo multicausal têm levado a limitações. Uma delas diz respeito à impossibilidade de conhecer o peso relativo de cada um dos fatores na determinação do fenômeno. Outra, ao fato dos modelos empíricos em epidemiologia trabalharem tais fatores isoladamente, sendo capazes, no máximo, de controlar os intervenientes, paradoxo que resulta na sua redução à unicausalidade. A sua aplicabilidade na formulação de políticas de saúde também esbarra na dificuldade de estabelecer prioridades para a atuação frente a inúmeras opções causais.

Dizem os autores, "... na dependência do conhecimento existente sobre o problema enfocado $e$ de acordo com interesses explicitados ou não, se adota um ou outro grupo articulado de fatores envolvidos 
no processo causal" (BARRETO; CARMO,1994). É sobretudo na prática que a multicausalidade se vê freqüentemente reduzida à unicausalidade, quer por insuficiência dos instrumentos de intervenção, quer porque as ações implementáveis são consideradas suficientes na abordagem rotineira dos problemas.

Dentre esses modelos de unicausalidade que acabam por operar na prática, Tesh apud BARRETO;CARMO,1994 distingue a teoria do germe, a dos estilos de vida, a ecologia ou ambiental e a teoria genética. A primeira delas, cujo auge coincide com o advento da bacteriologia, ainda se mantém como alternativa importante, a despeito da diminuição relativa do número de casos de doenças infecciosas na maioria dos países, frente ao aumento das enfermidades crônico-degenerativas. Isso porque as estratégias de intervenção nela ancoradas podem se limitar às medidas voltadas ao controle do agente infeccioso, tendo como alvo privilegiado o corpo humano individualizado. Como exemplos têm-se os programas de vacinação e as terapêuticas antibacterianas.

Em segundo lugar, a teoria dos estilos de vida, na qual a gênese da doença aparece associada ao modo de vida das pessoas, seus hábitos e os comportamentos de risco a que se submetem, tais como o estresse, a vida sedentária, a alimentação inadequada, a drogadição e mesmos determinadas práticas sexuais, aî se encaixando, por exemplo, a AIDS e as doenças sexualmente transmissiveis. Como conseqüência, as intervenções estariam voltadas justamente para medidas individuais de proteção à saúde e à adoção de estilos de vida mais saudáveis, com o devido estímulo e apoio de programas de educação em saúde. Dentro dessa concepção, a informação e os programas de educação, mais gerais ou mais específicos, aparecem como uma alternativa importante de intervenção no processo saúde-doença.

No terceiro modelo de interpretação, a teoria ambiental, o meio ambiente, especialmente aquele deteriorado pelos processos de industrialização, é tido como o desencadeador da doença, como no caso da cólera, do dengue, entre outras. Contraditoriamente, mesmo nesse modelo, as alternativas de superação também são remetidas à esfera da proteção individual, pouca atenção sendo dada às formas de organização da produção e de utilização da tecnologia.

Por último, a teoria genética, vem ganhando força à medida em que são divulgados os resultados das pesquisas do genoma humano. Retoma-se assim a vertente ontológica, sendo que neste caso as explicações para o adoecimento estariam adormecidas nos códigos genéticos individuais, o que constitui " ... a expressão máxima da biologizacão na causação das doenças e da individualização nas práticas de saúde". (BARRETO; CARMO,1994:24)

\section{UMA NOVA MANEIRA DE PENSAR SAÚDE E DOENÇA}

Como alternativa para a superação dos modelos causais clássicos, centrados em ações individuais, como os métodos diagnóstico e terapêuticos, a vacinação, a educação em saúde, ainda que dirigidos aos denominados grupos de risco, haveria que privilegiar a dimensão coletiva do fenômeno saúde-doença, através de modelos interativos que incorporassem ações individuais e coletivas.

Uma nova maneira de pensar a saúde e a doença deve incluir explicações para os achados universais de que a mortalidade e a morbidade obedecem a um gradiente que atravessa as classes sócio-econômicas, de modo que menores rendas ou status social estão associados a uma pior condição em termos de saúde. Tal evidência constituise em um indicativo de que os determinantes da saúde estão localizados fora do sistema de assistência à saúde. Ou seja, o fato de que os gradientes de mortalidade e morbidade atravessam as classes sociais, mantendo-se estáveis ao longo de grandes períodos de tempo, ainda que as principais causas de adoecimento se modifiquem, indica que fatores adjacentes influenciam a susceptibilidade às doenças, mesmo quando pensados como fatores de risco. Destaca-se assim o seu caráter pouco específico, dado que se situam em um nível mais geral que o da etiologia das doenças. Assim sendo, as politicas em resposta a doenças específicas podem não chegar a atingi-los. (EVANS;STODDART, 1990)

A origem da busca pela assistência, a que se convencionou chamar demanda, é um carecimento, ou a falta de algo, alguma coisa a ser corrigida, um sofrimento. $\mathrm{O}$ seu reconhecimento, quer pelo individuo que o manifesta, quer pelos prestadores da assistência que o interpretam como passivel de intervenção, eleva o carecimento à condição de necessidade. Ocorre que as instituições prestadoras de assistência à saúde "lêem" como necessidades apenas aqueles carecimentos que fazem parte do "cardápio de necessidades" socialmente reconhecidas enquanto tal, naturalizadas e reificadas. Também o demandante, com base em suas experiências pregressas, encaminha-se aos serviços tendo em mente uma "solução antevista", reiterando a intervenção. (SCHRAIBER; MENDES-GONÇALVES, 1996)

Na maioria das sociedades, a política de assistência à saúde tem sido utilizada como sinônimo de política de saúde, em função de sua aplicabilidade mais imediata e de sua aparente cientificidade (EVANS; STODDART, 1990). Em conseqüência, uma grande proporção dos recursos das sociedades modernas é gasta na produção e distribuição do que se denomina assistência à saúde, refletindo uma concepção disseminada de que o seu uso é fundamental para a saúde dos indivíduos e das populações. Disso resulta que as políticas de saúde coletiva sejam predominantemente politicas de assistência à saúde, como resposta às demandas sociais por saúde. (CAMPOS, 1994) 
Tais demandas são identificadas em termos de um conceito clínico, ou seja, a doença, tal como definida profissionalmente, de modo que a assistência poderia ser melhor definida como assistência à doença. A saúde, em contrapartida, é definida por um conceito negativo, a ausência de doença ou dano. A aparente vantagem significativa de tal definição, e que ajuda a explicar a sua ampla aceitação, decorre do fato de poder ser representada por fenômenos quantificáveis, como mortalidade e sobrevivência, incidência ou prevalência de determinadas condições mórbidas. O sistema de saúde elegeu-se em representante autorizado para a tradução do conhecimento científico na melhoria da saúde ou no controle das doenças, através de intervenções que deveriam ser cada vez mais eficazes porque oriundas de uma ciência que se pensa como progressivamente melhor. (EVANS; STODDART, 1990)

O conhecimento cada vez mais passou a ser definido como o resultado da aplicação de métodos reducionistas de intervenção, aplicados ao extremo, numa perspectiva newtoniana. Tão grande foi a eficácia obtida que em meados deste século os provedores de assistência à saúde haviam conquistado um domínio institucional e intelectual tamanho que passaram a deter a prerrogativa da definição da saúde e das estratégias para garanti-la. Evidências há, entretanto, de que essas práticas estão muito frouxamente conectadas ao conhecimento científico, ao contrário do que assegura a retórica oficial. (GOODMAN, 1992; McKINLAY; BEAGLE HOLF, 1989)

O sucesso do sistema de assistência à saúde em ocupar o centro da arena intelectual e política e em drenar recursos para as suas atividades reforça as expectativas sociais acerca de sua potência, ainda que, por outro lado, tenha como conseqüência inevitável um certo grau de desapontamento e desilusão quando confrontado com a impossibilidade de fazer cumprir as suas promessas. (EVANS; STODDART, 1990)

Se, por um lado, a prática médica e, por extensão, as demais práticas em saúde, são trabalhos que buscam atender as necessidades humanas, intervindo sobre "valores vitais", biológicos e psicológicos, por outro essas práticas constituem-se em valores de troca, de modo que tais processos de trabalho, mesmo que reconhecidos por sua dimensão técnica, definem-se à margem da própria técnica", no conjunto articulado das práticas sociais em que se inserem. (NUNES, 1986)

\section{CONSIDERAÇÕES FINAIS}

A compreensão acerca dos determinantes da saúde das populações, assim como a discussão e a formulação de políticas de saúde têm sido grandemente prejudicadas pela perpetuação de instrumentos de interpretação incompletos, obsoletos ou equivocados.
A distância entre esses determinantes e o foco primário da política de saúde na provisão de assistência à saúde decorre em parte da persistência desses modelos como instrumentos teóricos de referência para a conceptualização dos determinantes do processo saúde-doença. (EVANS; STODDART, 1990)

\section{A Teoria da Intervenção Práxica da} Enfermagem em Saúde Coletiva (EGRY,1996) propõe uma forma sistematizada para captar, interpretar e intervir no fenômeno, no caso o processo saúde-doença, tendo em vista suas manifestações nas dimensões singular, particular e estrutural da realidade. A dimensão singular, relativa aos individuos e suas famílias, é aquela onde em última instância manifestam-se os processos que levam ao adoecimento e à morte, como expressão das formas de reprodução social de grupos sociais distintos, ou seja, a dimensão particular. Ambos articulam-se aos processos de produção e reprodução social da coletividade em que se inserem, cujo contexto e estrutura social são historicamente determinados, constituindo assim a dimensão estrutural. A captação, interpretação e intervenção seguir-se-ia a contínua reinterpretação do fenômeno, de forma práxica, constituindo a unidade dialética teoria-prática.

A abordagem dos problemas irá determinar quais evidências serão privilegiadas em detrimento de outras. Ou seja, a despeito das evidências das correlações entre mortalidade e classe social, grau de instrução, renda, posição na hierarquia social, tais relações não são levadas em conta na formulação das políticas de saúde. Essas mesmas politicas são, todavia, bastante permeáveis à incorporação de novas tecnologias, sob a forma de novas drogas, equipamentos, métodos diagnósticos ou terapêuticos. É negligenciado o fato de que pessoas estejam adoecendo e morrendo em conseqüência de processos que não estão diretamente conectados com a assistência à saúde. (EVANS; STODDART, 1990)

Um novo instrumento intelectual para a apreensão da saúde e da doença deve levar em conta a distinção entre a doença, tal como definida pelo sistema da assistência à saúde e a saúde, tal como percebida pelos indivíduos. Ademais, deve incluir a dimensão do bem-estar, um conceito ainda mais amplo, no qual a contribuição da saúde não é a única e nem a mais importante. O sofrimento experienciado pelas pessoas, suas famílias e grupos sociais não corresponde necessariamente à concepção de doença que orienta os provedores da assistência.

A doença não é mais que um constructo que guarda relação com o sofrimento, com o mal, mas não lhe corresponde integralmente. Quadros clinicos semelhantes, ou seja, com os mesmos parâmetros biológicos, prognóstico e implicações para o tratamento, podem afetar pessoas diferentes de forma distinta, resultando em diferentes manifestações de sintomas e desconforto, com comprometimento diferenciado de 
suas habilidades de atuar em sociedade. O conhecimento clínico pretende balizar a aplicação apropriada do conhecimento e da tecnologia, o que implica que seja formulado nesses termos. No entanto, do ponto de vista do bem-estar individual e do desempenho social, a percepção individual sobre a saúde é que conta. (EVANS; STODDART, 1990)

A instauração de "espaços de emergência de necessidades" no interior dos serviços, de tal forma que se oponham ao seu caráter instaurador de necessidades reificadas, pode ajudar a resgatar "... valores que foram negativados ao longo das opções históricas que elegeram a atual forma dominante de construção da vida social ...", espaços que se abram para os carecimentos ainda não incorporados pela ciência tradicional. (SCHRAIBER; MENDES-GONÇALVES, 1996)

Isso seria conseguido na medida em que se evitasse que as necessidades de saúde fossem reduzidas a processos fisio-patológicos, em que se buscassem formas de assistir que fossem cada vez mais "totalizadoras" e não meramente a somatória de especificidades tecnológicas, em que se resgatasse a subjetividade, quer da coletividade, quer dos trabalhadores em saúde, como parte desse processo de inovação. (SCHRAIBER; MENDES-GONÇALVES, 1996)

\section{REFERENCIAS BIBLIOGRÁFICAS}

ABED, L.C. La enfermedad en la historia: una aproximación política, cultural e socioeconómica. Córdoba, Universidad Nacional de Córdoba, 1993.

ANDERY, M.A. et al. Para compreender a ciência: uma perspectiva histórica. Rio de Janeiro, EDUC-Espaço e Tempo, 1988.

BANTA, D.; DAHUCE, B.R. Health care technology and its assessment: an international perspective. Oxford, Oxford University Press, 1993. cap.2, p.13-57.

BARATA, R.B. A historicidade do conceito de causa. 2 ed. Rio de Janeiro, ENSP/ABRASCO, 1990.(Epidemiologia 1 Textos de Apoio)

BARRETO; M. L.; CARMO, E.H. Situação de saúde da população brasileira: tendências históricas, determinantes e implicações para as politicas de saúde. Informe Epidemiol. SUS. v. III, n. 34,1994

Mudanças em padrões de morbimortalidade: conceitos e métodos. In: MONTEIRO, C. A. Velhos e novos males da saúde no Brasil: a evolução do país e suas doenças. São Paulo, Hucitec/NUPENS-USP, 1995. P.1-30.

CAMPOS, G. W. S. Considerações sobre a arte e a ciência da mudança: revolução das coisas e reforma das pessoas: o caso da saúde. In: CECÍLIO, L. C. O. (org.) Inventando a mudança na saúde. São Paulo, Hucitec, 1994. p. 29-87.

CANGUILHEM, G. O normal e o patológico. Rio de Janeiro, Forense-Universitária, 1978.
CASTEllanos, B. E. P.; BeRTOlOZZI, M. R. A questão das teorias interpretativas da "saúde" e da "doença". São Paulo, 1991. /mimeografado/.

CZERESNIA, D. Do contágio à transmissão: ciência e cultura na gênese do conhecimento epidemiológico. Rio de Janeiro, FIOCRUZ, 1997.

EGRY, E.Y. Saúde coletiva: construindo um novo método para a enfermagem. São Paulo, Ícone, 1996.

EVANS, R.G.; STODDART, G.I. Producing health, consuming health care. Soc.Sci. Med., v.2, n. 31, p. 1347-63, 1990.

FACCHINI, L.A. Por que a doença? : a inferência causal e os marcos teóricos de análise. In: ROCHA, L.E.; RIGOTO, R.M.; BUSCHINELLI, J.T.P. (org.) Isto é trabalho de gente? : vida, doença e trabalho no Brasil. Petrópolis, Vozes, 1994. p. 33-55.

GARCIA, J. C. Historia de las instituciones de investigación en salud en América Latina: 1880-1930. Educ. Med. Salud. v.5, n.1, p. 71-87, 1995.

GOODMAN,C. It's time to rethink health care technology assessment. Int. J. Assess. Health Care. v.8, 335-58, 1992.

LUZ, M.T. As instituições médicas no Brasil: instituição e estratégia de hegemonia. Rio de Janeiro, Graal, 1979.

MACHADO, R. et al. Danação da norma: a medicina social e a constituição da psiquiatria no Brasil. Rio de Janeiro, Graal, 1978.

McKINLAY,J.B.; McKINLAY,S.M.; BEAGLEHOLE, R. A review of the evidence concerning the impact of medical measures on recent mortalilty and morbidity in the United States. Int.J. Health Serv.,v.19, n.2, p.181-208, 1989.

NUNES, E.D. (org.) Ciencias sociales y salud en la America Latina: tendencias y perspectivas. Montevideo, OPS/ CIESU, 1986.

ROSEN, G. Uma história da saúde pública. São Paulo/Rio de Janeiro, Hucitec/ UNESP-ABRASCO, 1994.

SALUM, M. J. L., BERTOLOZZI, M. R., OLIVEIRA, M. A. de C. O coletivo como objeto do conhecimento e da prática de enfermagem: as continuidades e descontinuidades da história. São Paulo, Escola de Enfermagem da Universidade de São Paulo, 1998. /mimeografado/

SCHRAIBER, L.B. ; MENDES-GONÇALVES, R.B. Necessidades de saúde e atenção primária. In: SCHRAIBER,L.B. et al. (org.) Saúde do adulto: programas e ações na unidade básica. São Paulo, Hucitec, 1996. p.29-46.

SILVA, G. R. As origens da medicina preventiva como disciplina do ensino médico. Rev. Hosp. Clin. Fac. Med. USP, v.28, p.91-4, 1979.

Avaliação e perspectivas da epidemiologia no Brasil. In: CONGRESSO BRASILEIRO DE EPIDEMIOLOGIA, 1, Campinas, 1990. Anais. Campinas, ABRASCO, 